Supporting Information

\title{
Aligned Organic Molecular Wires in Methionine Nanofilm Growth on $\operatorname{Si}(111)-\sqrt{ } \mathbf{3} \times \sqrt{ } \mathbf{3}-\mathbf{A g}$
}

\author{
Hanieh Farkhondeh, Fatemeh. R. Rahsepar, $†$ Lei Zhang, Kam Tong Leung* \\ WATLab, and Department of Chemistry, University of Waterloo \\ Waterloo, Ontario, Canada N2L3G1
}

* Corresponding author. Email: tong@uwaterloo.ca

$\dagger$ Present address: School of Chemistry, College of Science, University of Tehran, Tehran, Iran. 


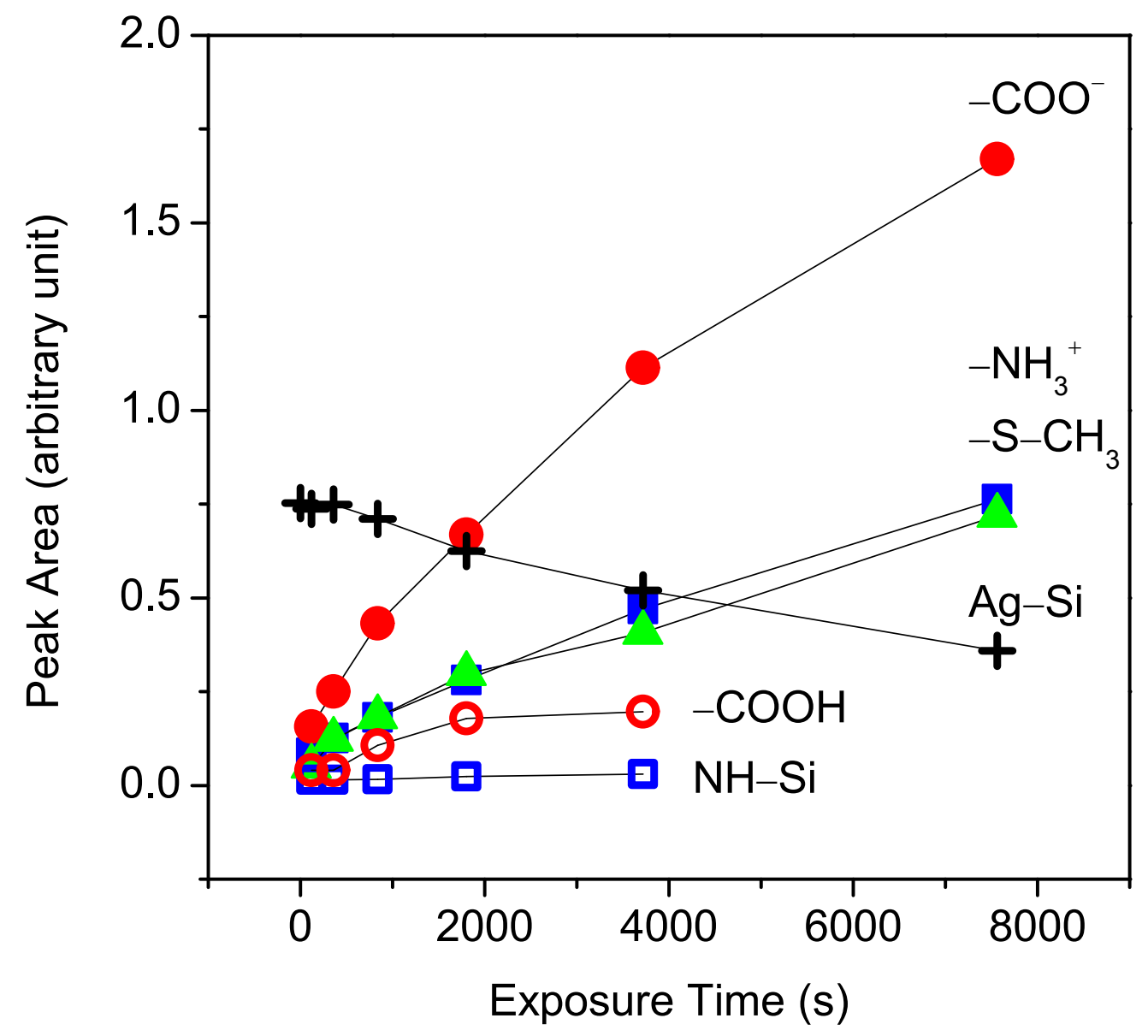

Figure S1. Peak areas of fitted XPS features in the $\mathrm{O} 1 \mathrm{~s}, \mathrm{~N} 1 \mathrm{~s}, \mathrm{~S} 2 \mathrm{~s}$ and Ag3d regions as functions of methionine exposure time on $\operatorname{Si}(111)-\sqrt{3} \times \sqrt{3}-\mathrm{Ag}$. 
Table S1. Binding energies (in $\mathrm{eV}$ ) of fitted peaks for various XPS core-level features and their corresponding assignments for different exposures of L-methionine on $\mathrm{Si}(111)-\sqrt{3} \times \sqrt{3}-\mathrm{Ag}$.

\begin{tabular}{|c|c|c|c|c|c|c|c|}
\hline $\begin{array}{c}\text { Core } \\
\text { level }\end{array}$ & Assignment & $120 \mathrm{~s}$ & $360 \mathrm{~s}$ & $840 \mathrm{~s}$ & $1800 \mathrm{~s}$ & $3720 \mathrm{~s}$ & $7560 \mathrm{~s}$ \\
\hline $\mathrm{O} 1 \mathrm{~s}$ & $-\mathrm{COO}^{-}$ & 531.8 & 531.8 & 532.8 & 531.9 & 532.0 & 532.0 \\
& $-\mathrm{COOH}$ & 532.6 & 532.7 & 532.7 & 532.6 & 532.6 & -- \\
\hline $\mathrm{N} 1 \mathrm{~s}$ & $\mathrm{NH}-\mathrm{Si}$ & 399.2 & 398.4 & 398.8 & 398.7 & 398.7 & -- \\
& $-\mathrm{NH}_{3}{ }^{+}$ & 401.8 & 401.8 & 401.9 & 402.0 & 402.0 & 402.0 \\
\hline $\mathrm{C} 1 \mathrm{~s}$ & $-\mathrm{CH}_{2}$ & 285.3 & 285.5 & 285.6 & 285.6 & 285.6 & 285.6 \\
& $-\mathrm{CH}_{2}-\mathrm{S}_{-} \mathrm{CH}_{3}$ & 285.9 & 285.9 & 286.0 & 286.0 & 286.0 & 285.9 \\
& $-\mathrm{CH}^{-\mathrm{NH}_{3}}{ }^{+}$ & 286.9 & 286.9 & 286.8 & 286.9 & 286.9 & 286.8 \\
& $-\mathrm{COO}^{-}$ & 288.6 & 288.7 & 288.9 & 288.9 & 288.9 & 288.9 \\
\hline $\mathrm{S} 2 \mathrm{~s}$ & $-{\mathrm{S}-\mathrm{CH}_{3}}^{2}$ & 228.4 & 228.4 & 228.4 & 228.4 & 228.4 & 228.4 \\
\hline
\end{tabular}



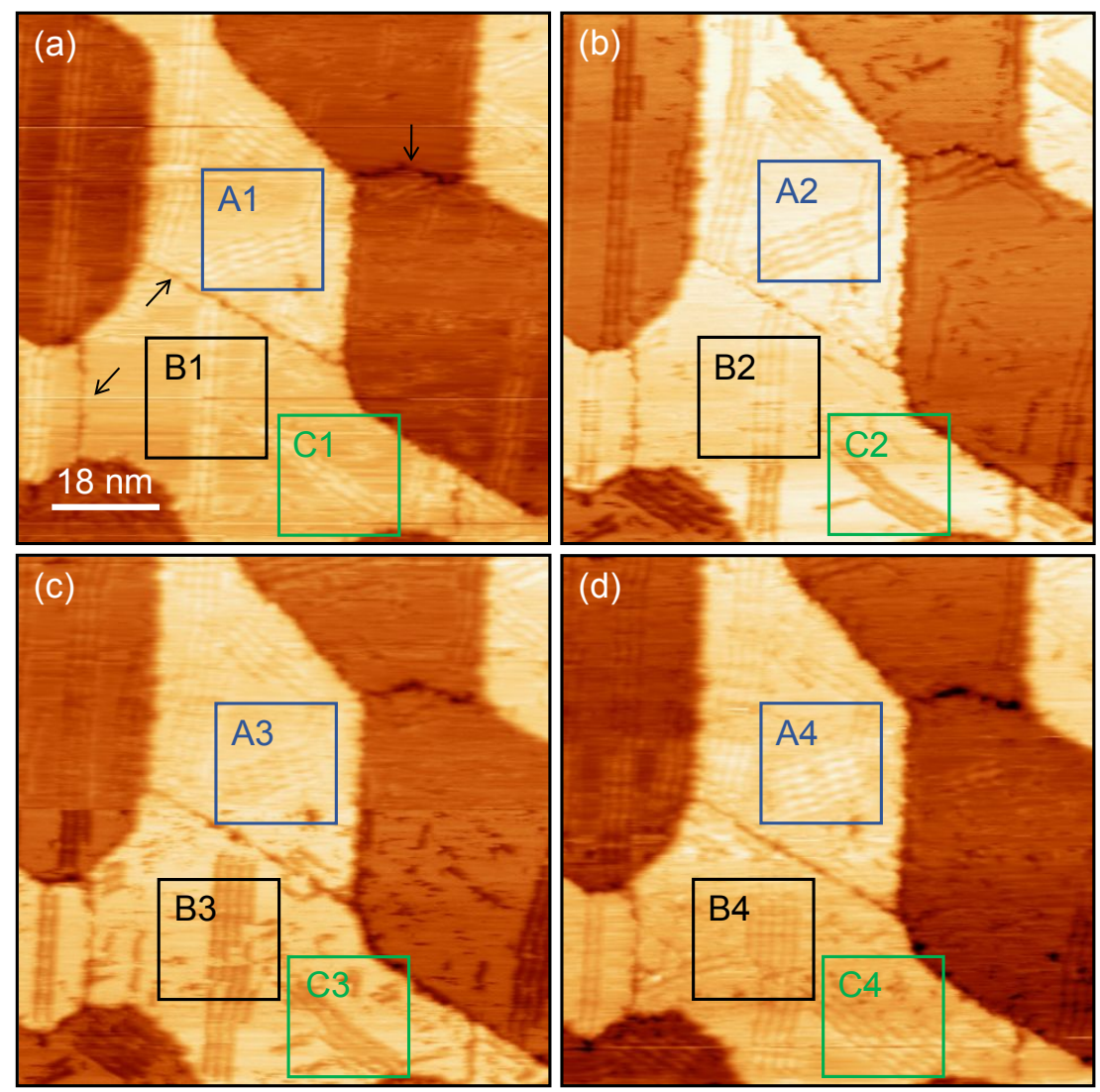

Figure S2. (a-d) Consecutive empty-state STM images of L-methionine with a 120-s exposure on $\operatorname{Si}(111)-\sqrt{3} \times \sqrt{3}-$ Ag collected at room temperature one after another with a scanning rate of 450 $\mathrm{nm} / \mathrm{s}$. Despite the somewhat diffuse features caused by the high mobility of the methionine molecules on the surface at room temperature, self-assembly of distinct molecular wires is clearly observed. The apparent instability in the quality of STM measurements over a fixed position and with fixed scanning parameters suggests the presence of mobile features on the surface. Tracking the changes appearing in the adsorbate island formation as a function of time further indicates the movement of methionine molecules on the surface at room temperature. The areas shown with open squares, A, B and C, mark such changes, i.e., the development of methionine molecular wires and nanograting as a function of time. For example, the number of stripes in the selected blue, black and green boxes appears to increase with time. All images are obtained with a sample bias of $+2.0 \mathrm{~V}$ and a tunneling current of $0.2 \mathrm{nA}$. 

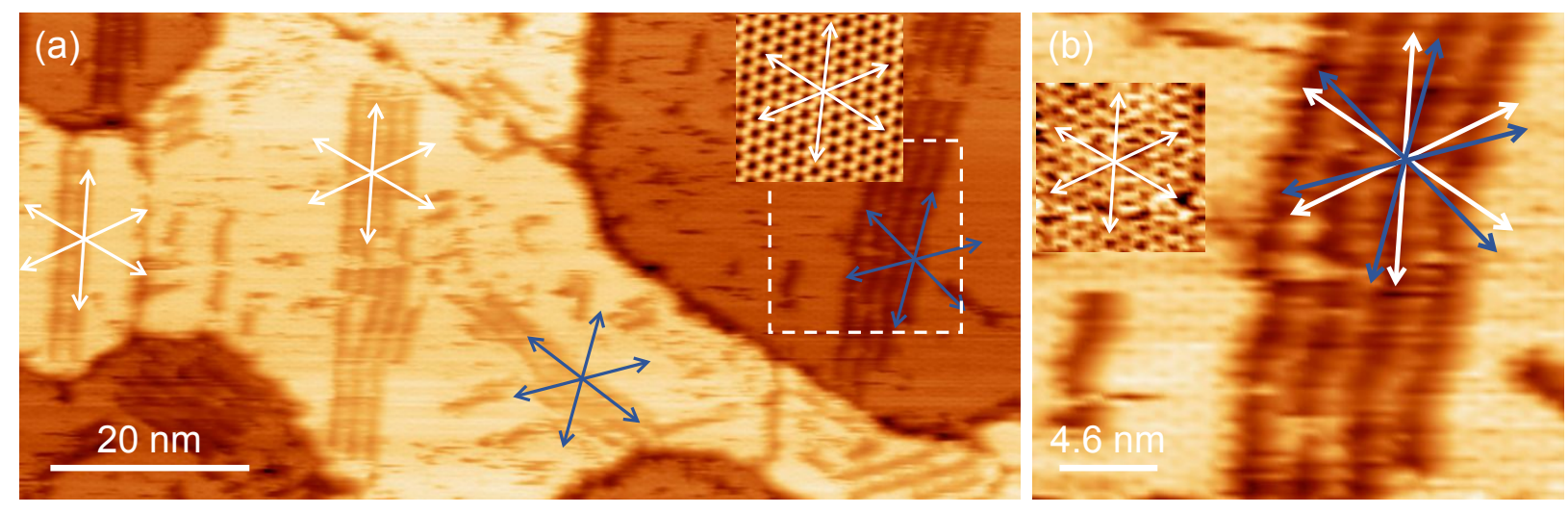

Figure S3. (a) Empty-state STM image of L-methionine with a 120-s exposure on Si(111)$\sqrt{3} \times \sqrt{3}-\mathrm{Ag}$ at room temperature, and (b) magnified image of a selected area marked by the open square in (a). An atomic-resolution image of the underlying $\sqrt{3} \times \sqrt{3}$-Ag structure of a clean sample obtained from a separate experiment (with a sample bias of $+0.3 \mathrm{~V}$ and tunnelling current of $2 \mathrm{nA}$ ) is shown as an inset in (a), and that of a different part of the same sample (not covered by methionine) is shown as an inset in (b), with the white arrows indicating the directions of the atomic close-packed rows of the $\sqrt{3} \times \sqrt{3}-\mathrm{Ag}$ structure along the $<11-2>$ directions. Two sets of domains of molecular wires with slightly different orientations are marked by (i) white arrows showing the molecular wires extended along the $<11-2>$ directions and (ii) blue arrows marking the plausible directions of molecular wires that are offset by $11^{\circ} \pm 2^{\circ}$ clockwise from the set of white arrows. This offset shows that some of the molecular wires are not perfectly aligned parallel to the surface atomic close-packed directions at room temperature. All images are obtained with a sample bias of $+2.0 \mathrm{~V}$ and a tunneling current of 0.2 $\mathrm{nA}$ at room temperature. 
Table S2. Top view of the optimized equilibrium adsorption configurations of methionine monomer at different adsorption sites (monoatomic or atop M1, diatomic or bridge D1, and triatomic or three-fold hollow T1 sites) and with different orientations with respect to the surface. The adsorption energies are in unit of eV while the bond lengths are in unit of $\AA$. To better illustrate the adsorption structure, only part of the slab (of the full $4 \times 4$ supercell) and only the topmost ( $\mathrm{Si}-\mathrm{Ag})$ layer for the model surface are shown. The most stable configurations with the most negative adsorption energies are labelled in bold.

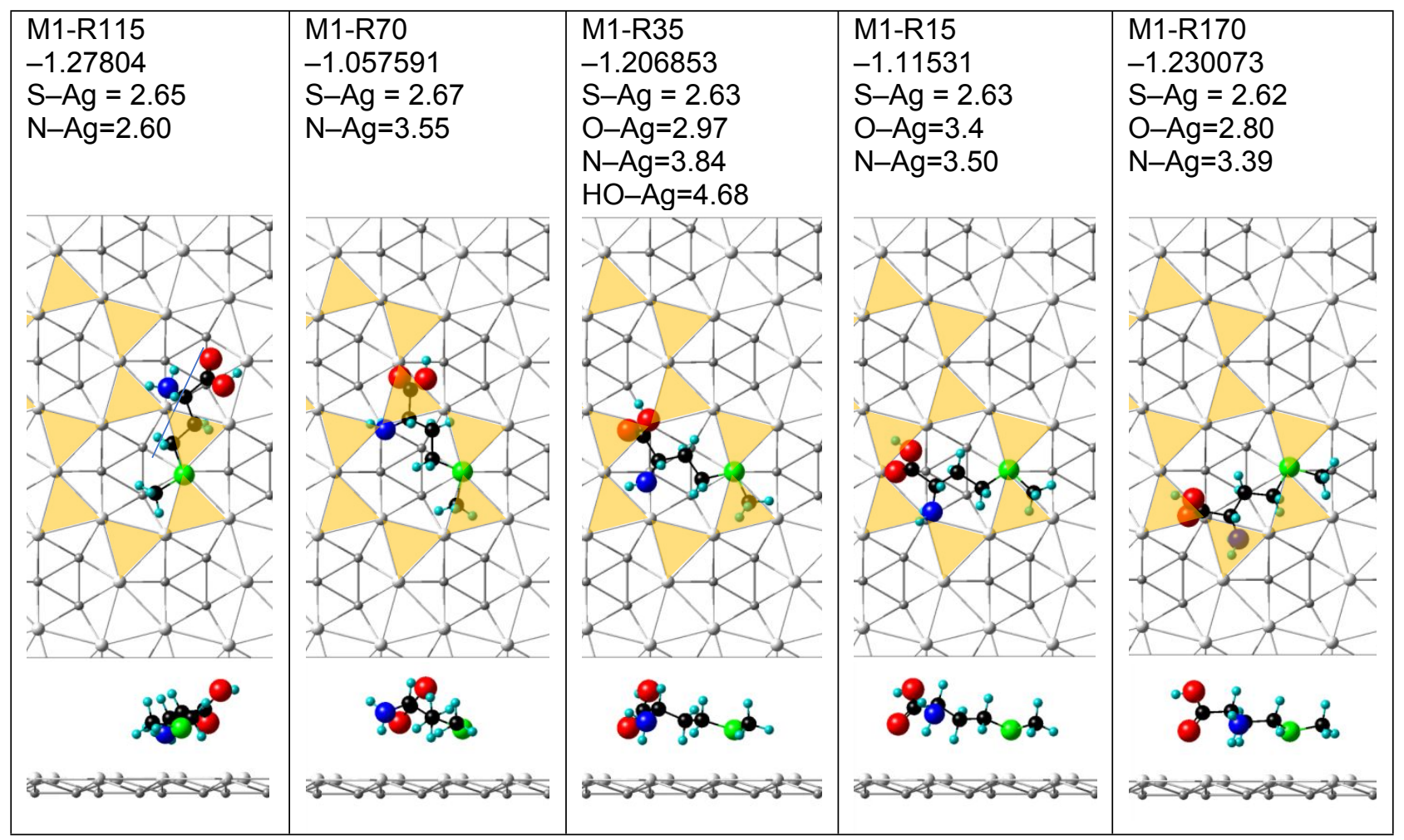


Table S2. (Continued)

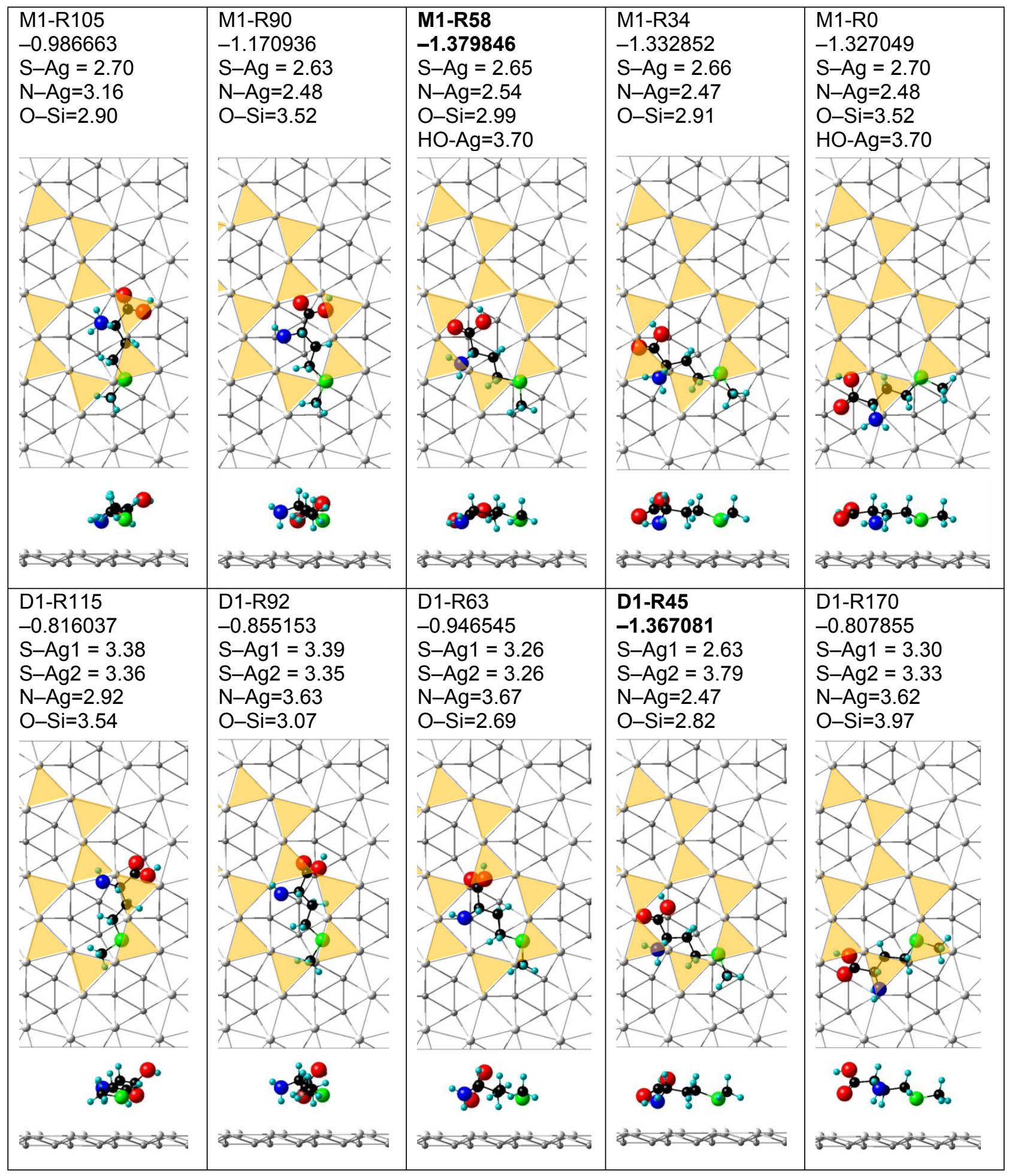


Table S2. (Continued)

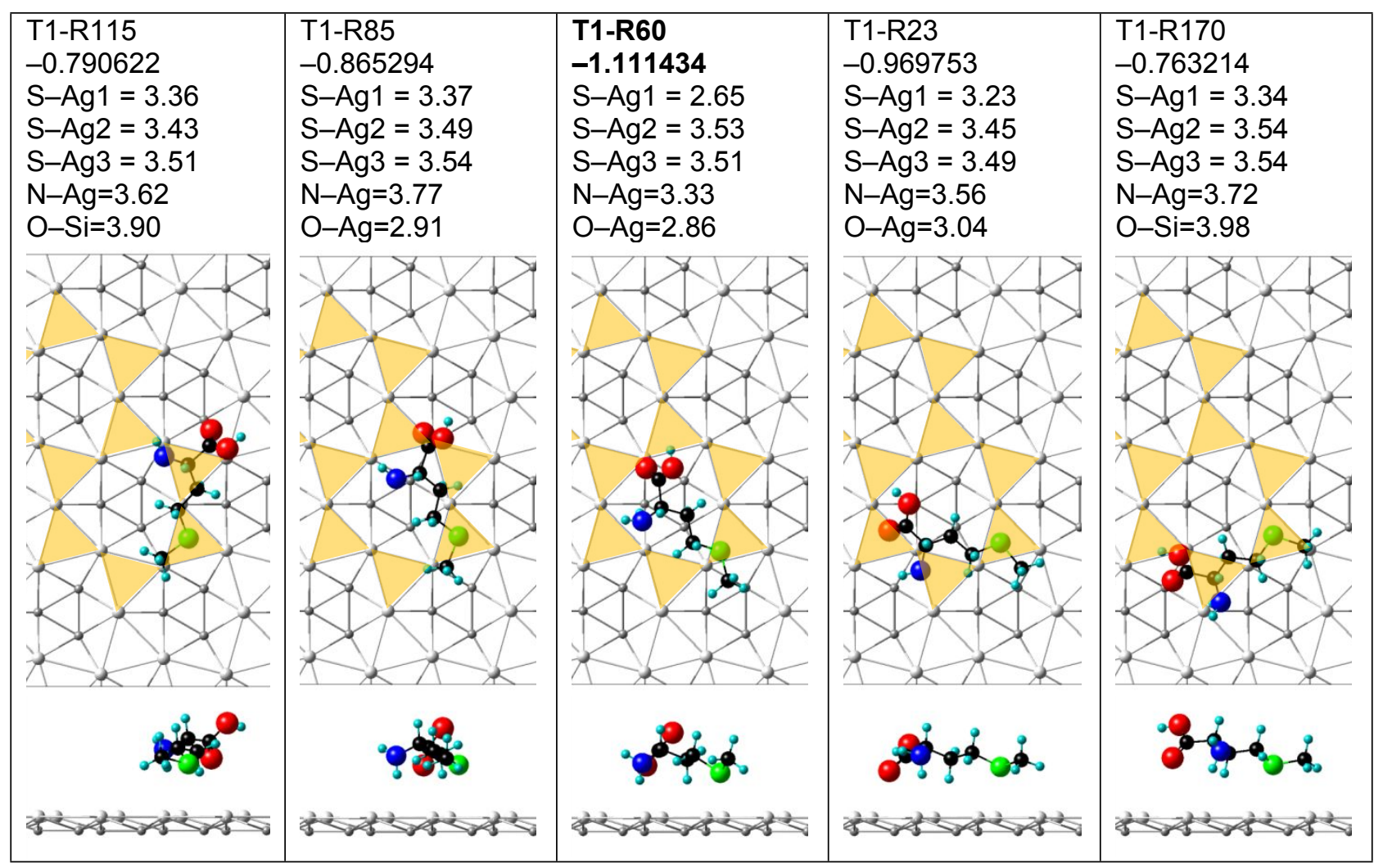


Table S3. Top view of the optimized equilibrium adsorption configurations of methionine antiparallel dimer at M1 adsorption sites and with different orientations with respect to the surface unit cell. The adsorption energies are in unit of $\mathrm{eV}$ while the bond lengths are in unit of $\AA$. To better illustrate the adsorption structure, only part of the slab (of the full $4 \times 4$ supercell) and only the topmost ( $\mathrm{Si}-\mathrm{Ag}$ ) layer for the model surface are shown. The most stable configuration with the most negative adsorption energy is labelled in bold.

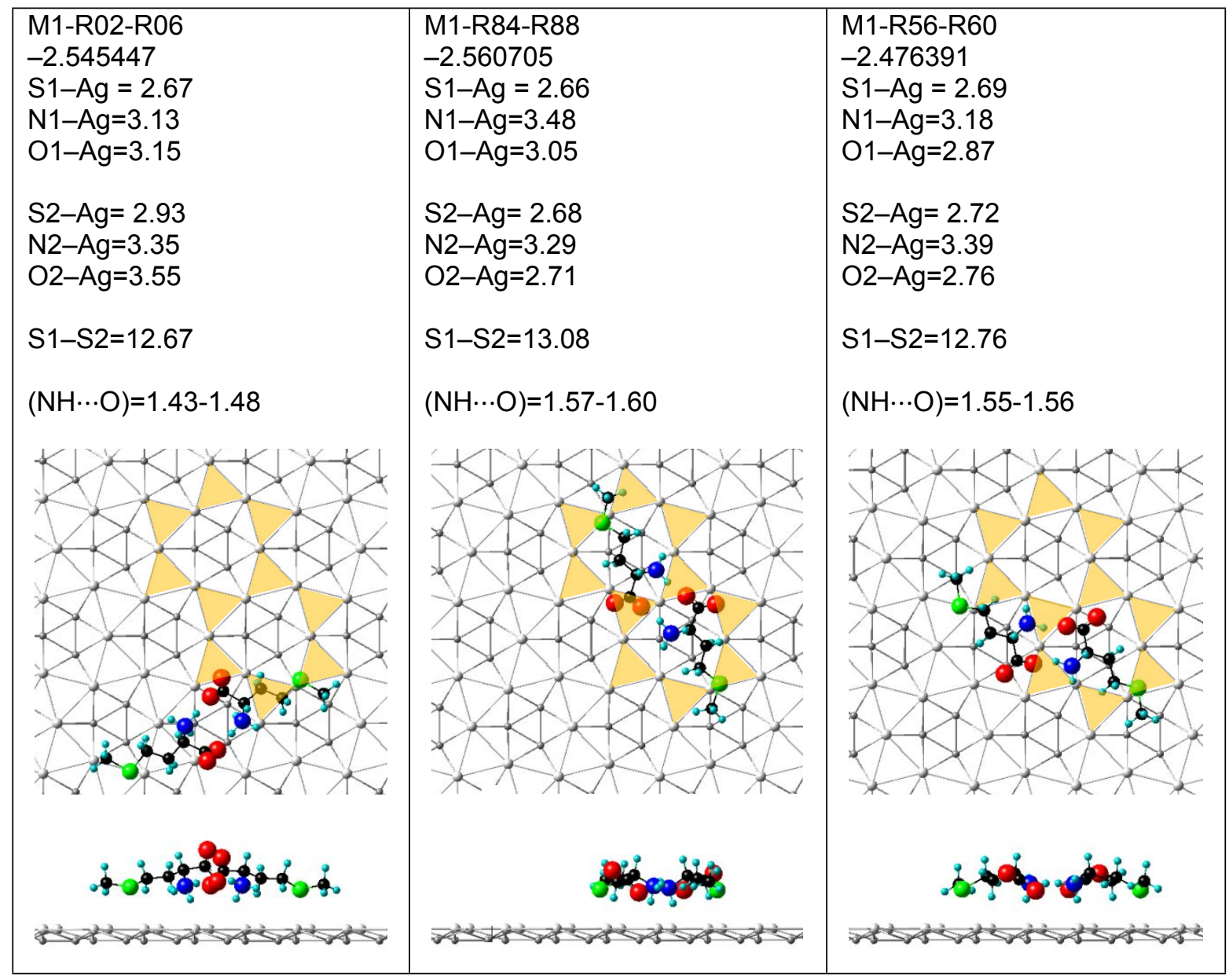


Table S3. (Continued)

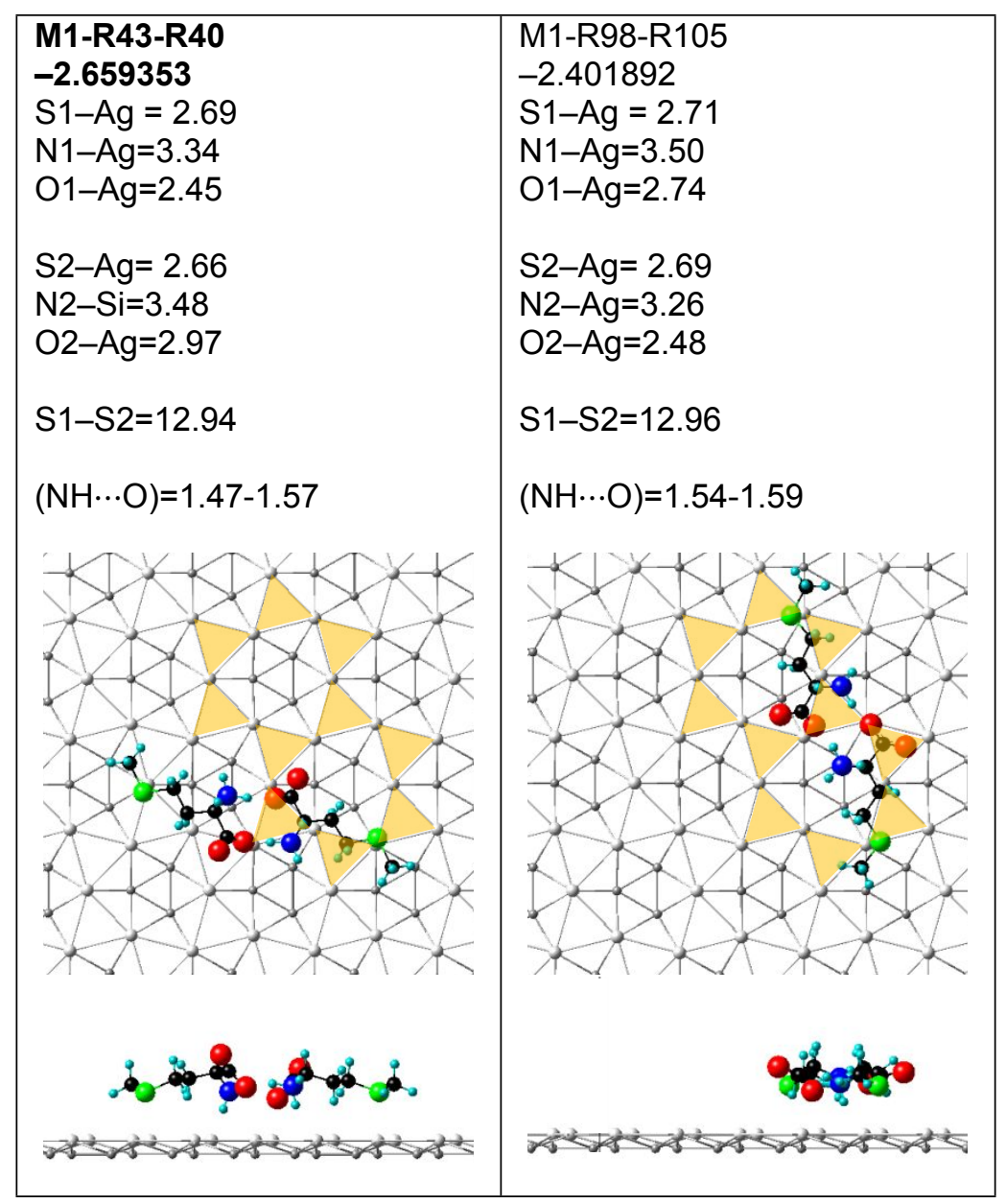


Table S4. Top view of the optimized equilibrium adsorption configurations of methionine parallel dimer at M1 adsorption sites and with different orientations with respect to the surface unit cell. The adsorption energies are in unit of $\mathrm{eV}$ while the bond lengths are in unit of $\AA$. To better illustrate the adsorption structure, only part of the slab (of the full $4 \times 4$ supercell) and only the topmost (Si-Ag) layer for the model surface are shown. The most stable configuration with the most negative adsorption energy is labelled in bold.

\begin{tabular}{l|l}
$\mathrm{M} 1-\mathrm{R} 105-\mathrm{R} 105$ & $\mathrm{M} 1-\mathrm{R74-R57}$ \\
-2.755241 & -3.055981 \\
$(\mathrm{~S}-\mathrm{Ag}) 1=2.66$ & $(\mathrm{~S}-\mathrm{Ag}) 1=2.64$ \\
$(\mathrm{~N}-\mathrm{Si}) 1=3.66$ & $(\mathrm{O}-\mathrm{Ag}) 1=3.51$ \\
$(\mathrm{O}-\mathrm{Ag}) 1=3.15$ & $(\mathrm{~S}-\mathrm{Ag}) 2=2.70$ \\
$(\mathrm{~N}-\mathrm{Ag}) 2=3.18$ \\
$(\mathrm{~N}-\mathrm{Ag}) 2=3.41$ \\
$(\mathrm{O} 1-\mathrm{Ag}) 2=2.89$
\end{tabular}


Table S4. (Continued)

\begin{tabular}{l|l}
$\mathrm{M} 1-\mathrm{R} 40-\mathrm{R} 33$ \\
-2.546756 & $\mathrm{M} 1-\mathrm{R} 170-\mathrm{R} 176$ \\
$(\mathrm{~S}-\mathrm{Ag}) 1=2.67$ & -2.685412 \\
$(\mathrm{~N}-\mathrm{Ag}) 1=3.43$ & $(\mathrm{~S}-\mathrm{Ag}) 1=2.66$ \\
$(\mathrm{O}-\mathrm{Ag}) 1=3.32$ & $(\mathrm{O}-\mathrm{Ag}) 1=3.52$ \\
$(\mathrm{~S}-\mathrm{Ag}) 2=2.68$ & $(\mathrm{~S}-\mathrm{Ag}) 2=2.67$ \\
$(\mathrm{~N}-\mathrm{Ag}) 2=3.37$ \\
$(\mathrm{O} 1-\mathrm{Ag}) 2=3.00$ \\
$(\mathrm{O} 2-\mathrm{Ag}) 2=3.17$ \\
$\mathrm{O} 1-\mathrm{O} 2=6 . \mathrm{Ag}) 2=3.64$ \\
$(\mathrm{O} 2-\mathrm{Ag}) 2=3.06$
\end{tabular}

